\title{
FROM SEARCH TO APPLICATION BUILDING - YAHOO PIPES FOR NOVICE PROGRAMMERS
}

\author{
Abhijit Sen, Kwantlen Polytechnic University, abhïit.sen@kwantlen.ca
}

\begin{abstract}
Teaching programming concepts to a group of students with different educational backgrounds and computing experiences is always a challenge for educators. In this paper the author attempts to explore methods to improve the teaching of computer programming concepts to students who may not have any prior experience to programming. This paper discusses the author's experience in teaching programming concepts using Yahoo Pipes to the students with no, or minimal programming experience. To make programming concepts fun and easy to understand and to retain student's attention and strengthen their motivation to learn, the author extensively uses applications students are familiar with.
\end{abstract}

Keywords: Programming, Pipes, Mashups

\section{INTRODUCTION}

Teaching computer programming to students with very little background in computing is not an easy task. Learning a new technology requires both time and motivation on the part of the learners. The best way of teaching programming to students has been extensively discussed in literatures [1,2]. The issues and challenges have been articulated in [1]. The teaching approaches and learning tools to be included in the curriculum for motivating students have been proposed in [4]. Most of the introductory courses introduce students with basic programming concepts such as control flow, basic data structures, functions using languages such as Java, C++, C, Visual Basic etc. [3]. The examples that are used to teach these basic concepts in most cases are too trivial with limited scope and have little or no interaction with external system. To most learners these examples appear to be uninteresting and do not resemble real-world programs they encounter while using computers. These examples do not present students with interesting and practical real-world problems that they care about solving. Moreover, the students find it difficult to learn the syntax and semantics of the new programming language and the associated integrated development environment (IDE).

Students learning of a programming language could be significantly enhanced if one uses examples that students are very familiar with. In this paper the author suggests how one can appreciably advance student motivation to learning a programming language by focusing on applications students are very familiar with, applications that are fun to use, interesting and relevant. The author found that visual programming framework provided by Yahoo Pipes is particularly useful in facilitating the effective teaching of programming constructs and to expose students to programming concepts. The student can start building simple mash up application without much effort using Yahoo Pipes. Yahoo Pipes uses a simple visual editor that enables user to fetch and manipulate various data sources, add user-defined inputs, and filter the content as needed. Yahoo Pipes support many important programming concepts such as: Modules, Pipes, Sort, Union, Input, LOOP, Functions. These can be used to build relevant realworld application easily. The proposed pedagogy is geared to undergraduate students taking introductory level of Computer Science courses with little or no background on theoretical computer science concepts and programming.

\section{INTRODUCTORY PROGRAMMING UNIT}

Yahoo Pipes provide number of built in modules to build Web content. Some of the important modules are:

- Data sources

- User Inputs 


\section{Issues in Information Systems}

Volume 13., Issue No., pp. No., 2012

- Operators

- URL

- String

- Date

- Location and

- Number

Mash up applications can be constructed using these built-in modules. The detailed specifications of these modules and simple examples are documented in Yahoo Pipes website [5].

The applications to be discussed in the class are chosen based on informal discussions with students. The majority of the students own personal computers and use Internet extensively. Other than using the computer for work and, emailing, these students extensively use computers for internet browsing, watching movies, listening to music, and social networking activities. To demonstrate that programming is an exciting, interesting and intellectually stimulating area of study, students will have the opportunity to create applications using the programs and features they use regularly. A few of these are listed below:

- Search for a particular item near a location - such as McDonald Restaurant in SanFrancisco area

- Display images - such as Stanley Park in Vancouver using Flickr

- Get Driving Directions - Using Google map find directions from source location to destination location

- Provide translation service from one language to another

The criteria in selecting these web applications are:

- Students are familiar with all these applications

- These applications are very easy to develop

- Program structure and logic to develop these applications is simple

- The logic is simple to debug

\section{USE OF YAHOO PIPES FOR APPLICATION BUILDING}

To teach the basics of programming concepts, Yahoo pipes are used with Internet browsers such as Internet Explorer or Firefox. An example may be used in the class to show how a simple web mash up application can be designed by incorporating series of simple steps using Yahoo pipes. In class demonstrations allow instructors to interactively explain programming concepts and different program modules supported by Yahoo pipes to the student.

In the following are given simple procedures instructor can use in the class room to demonstrate how mash up web application can be constructed using various constructs available in Yahoo pipes framework. The example will consist of the following steps:

- Understand and analyze the programming problem to be solved;

- Design and choose the user input if any;

- Select appropriate Yahoo pipes module and link them to implement the solution

- Execute the application and view the results

- Explain associated programming concepts

\section{PROGRAMMING EXAMPLES USING YAHOO PIPES}

Using simple drag and drop technique users can choose any module and place it on the editor. Screen shots of all examples with live links are shown in Figure 1 to Figure 8 in Appendix 1. Users can experiment with the working examples using the live links in Appendix 1. 


\section{Issues in Information Systems}

Volume 13., Issue No., pp. No., 2012

The display in Figure 1 below shows a typical example used in the class where user can search for a restaurant name within the vicinity of a particular city.

- Log on to Yahoo! Pipes

- Click on Create a New Pipe to display the visual editor. The list of modules (such as Sources, User Inputs, Operators, URL, String, Date etc.) is displayed on the left.

- Drag two times Text Input modules from User Inputs category. The input modules allow users to feed input information into completed Pipe when you run it - such as number of restaurants, the name of the city

- Drag Yahoo Local module from the Sources and drop it on editing area.

- Connect a Pipe from input module (such as search item)to Find input box of the Yahoo Local module, and another pipe from input module (such as name of city) into location box of Yahoo Local module

- Type 20 miles in the within box of Yahoo Local module

- Drag Truncate module from the Operator and drop it on editing area

- Connect output Pipe of Yahoo Local module to input of Truncate module

- Connect output pipe from Truncate module to input of the Pipe Output module.

- To test click on the Yahoo search module and result of this is displayed in a Debugger field at the bottom of the screen.

- Click Save (top right), give the pipe a name.

- Click Run Pipe... at the top of the screen to execute.

The modules for of example 1 are shown in Figure 1. The output of example 1 is shown in Figure 2.

This simple example clearly illustrates the two basic concepts:

- Modules- perform specific tasks - or in other word provides a service

- Pipes- links different modules together to create functions that meet ones needs.

Many interesting applications can be built using the various modules available, such as User Inputs, Operators, URL, String, Location, etc.

Example 2 allows one to search for images using Flickr.

- Drag three times Text Input modules from User Inputs category. The input modules allow users to feed input information into completed Pipe when you run it - such as number of images, the name of the city and the image name.

- Drag the Flickr module from sources.

- The above inputs can be fed into other modules. Connect the appropriate output of each of the Input modules to the corresponding fields in Flickr module. For example number of images from Input module can be connected num field of Flickr module.

- Drag the Sort module from the Operator and drop it on editing area

- Connect a Pipe from Flickr module to input of the Sort module

- Connect a Pipe from Sort module to input of the Pipe Output module

- Save and Run as in Example 1.

The modules are shown in Figure 3.

The output of example 2 is shown in Figure 4.

Example 2 illustrates the three concepts:

- Inputs - let users feed input information into various modules 


\section{Issues in Information Systems}

Volume 13., Issue No., pp. No., 2012

- Parameters- are list of values passed to a module that can perform its function on many different values. In the example Flickr module can display 4, 5,6 or any number of images depending on what values user inputs.

- Functions- perform operations. Flickr module uses Find function to locate the images specified and display the images on a map, as a list or as a slide show. One can use Sort function to sort the images in alphabetical order.

The output of example 2 is shown in Figure 4.

Example 3 allows one to sort and translate hockey feeds from two sites.

This particular example illustrates various useful computing terms /concepts:

- Sort - sort items in either ascending or descending order.

- Union - merges items into a single list of items.

- Truncate - lets you limit the number of items generated.

- Sort, Union, and Truncate modules can be found in the Operations category of Yahoo pipes

- LOOP - gives the ability to execute a module more than once. In the example, when the data feed is connected to the Loop module, the sub-module Translate is run once for each item in the input feed. The Loop module belongs to the category of Operator Modules

- Assignment - allows one to assign a value of a data item to another data item. In this example the result of translation to French text is stored in the data called item. description and item. title.

- Translate module from String category takes a text item -- such as an element from a feed -- and translates it from one language to another.

The modules are shown in Figure 5.

The output of example 3 is shown in Figure 6.

Example 4 Allows news item to be retrieved from CTV and CBC sources and tagged the items with source name (such as CTV/CBC).

As seen in figure three new concepts String Builder, URL Builder, Rename were introduced in this example by incorporating the modules below:

String Builder - builds a string from multiple substrings. In this example substrings source and destination location are concatenated data name and fed into search path of URL Builder module.

URL Builder - allows one construct complex URL. In this example URL is built for Google map specifying source and destination as query parameters.

Fetch Data - gets the current data specified by the URL created by URL Builder. The output of this module is fed to Rename module to create appropriate Google map information for display.

Rename - changes the existing element name to a new name. In this example geographic coordinates (item.Point.coordinates) data provide by Google Map module is converted to name (y:location.lat, and y:location.lon) recognized by Google interactive map. The output is fed into pipe output module.

The modules are shown in Figure 7

The output of example 4 is shown in Figure 8.

The reasons for selecting these particular examples are many:

- Enables student to create application using friendly visual programming techniques. 


\section{Issues in Information Systems}

Volume 13., Issue No., pp. No., 2012

- Allows student to work with different program module.

- Program components such as Modules, Loops, Assignments, and Pipes etc. can easily be explained as natural steps of programming logic.

- Teaches student how to link various modules to perform useful tasks to create interesting applications.

- Requires no new learning curve to understand a development environment as most students have used internet extensively.

\section{IN CLASS ASSIGNMENTS}

Each class consists of a short lecture component followed by in class assignments. The lecture component covers the fundamental programming topics. The hands on in class assignments enable the students to practice the concepts discussed in the lecture. The course is delivered in a class room equipped with computers for each student, facilitating direct teacher student interaction. This mode of delivery of the course materials with short lesson followed by hands on practice is found to be very effective in dealing with difficulties novice students encounter in learning programming fundamentals. Students are encouraged to enhance the features of the assignments using materials from textbooks or any available online resources.

\section{BENEFITS}

The use of Yahoo Pipes to develop mash up web applications familiar to students to supplement teaching introductory programming concepts provides many benefits:

- Provides students with practical skills to program and develop simple, but interesting applications within a short period.

- Facilitates instructor to explain the program structure with real and engaging examples.

- Motivates students to learn as the applications used are based on students' interests and level of program complexity is minimal.

- Enables learners to experiment with different code structure without changing the external behavior of the program.

- Enables students to capture different concepts such as - modules, sequence, loop, sort, union, search and pipes etc.

\section{CONCLUSIONS}

The author finds that teaching computer programming using familiar applications provided a motivating environment for students and enhanced their level of excitement. Students are sufficiently engaged and found the in class assignments fun and useful. Students were extremely positive with the new programming skills they learned, and are willing to apply them for new problems. There is no formal survey taken from students to get student's feedback regarding the proposed approach of teaching programming using Yahoo pipes. However author's overall experience with student's performance is very encouraging. Although students were apprehensive about programming before the lessons, they felt lack of prior programming experience has not affected their understanding of programming concepts and developing simple web applications. Students have very positive experience using visual programming environment provided by Yahoo Pipes.

\section{ACKNOWLEDGMENT}

The author wishes to thank the anonymous reviewers for helpful suggestions and to Mr. Arnab Sen, Technical Project Manager, Liquid Campaign, South Korea for reviewing the manuscript and making constructive comments to improve the paper. 


\section{Issues in Information Systems}

Volume 13., Issue No., pp. No., 2012

\section{REFERENCES}

1. Butler, M., Morgan, M. (2007) 'Learning challenges faced by novice programming students studying high level and low feedback concepts ', Proceedings of ascilite 2007 conference ,Singapore, December 2-5, pp. .99107.Available: http://www.ascilite.org.au/conferences/singapore07/procs/butler.pdf

2. Gomes, A., Mendes, A.J. (2007) 'An environment to improve programming education', Proceedings of the 2007 international conference on Computer systems and technologies, June 14-15, Bulgaria, pp. IV.19-1-IV.196.Available: http://ecet.ecs.ru.acad.bg/cst07/Docs/cp/sIV/IV.19.pdf

3. de Raadt, M, Watson, R, Toleman, M (2002) 'Language Trends in Introductory Programming Courses', Informing Science InSITE, June 2002 , pp. 329-337.Available:

http://proceedings.informingscience.org/IS2002Proceedings/papers/deRaa136Langu.pdf

4. Matthíasdóttir, A (2006) 'How to teach programming languages to novice students? Lecturing or not? ', International Conference on Computer Systems and Technologies - CompSysTech'06, Bulgaria, June 15-16, pp. IV.13-1-IV.13-7.Available: http://ecet.ecs.ru.acad.bg/cst06/Docs/cp/sIV/IV.13.pdf

5. Yahoo Pipes Documentation. Available: http://pipes.yahoo.com/pipes/docs 


\section{Issues in Information Systems}

Volume 13., Issue No., pp. No., 2012

\section{APPENDIX 1: SCREEN SHOTS OF SELECTED EXAMPLES WITH LIVE LINKS}

Example 1: Yahoo Local Search (http://tinyurl.com/6p2q4ek)

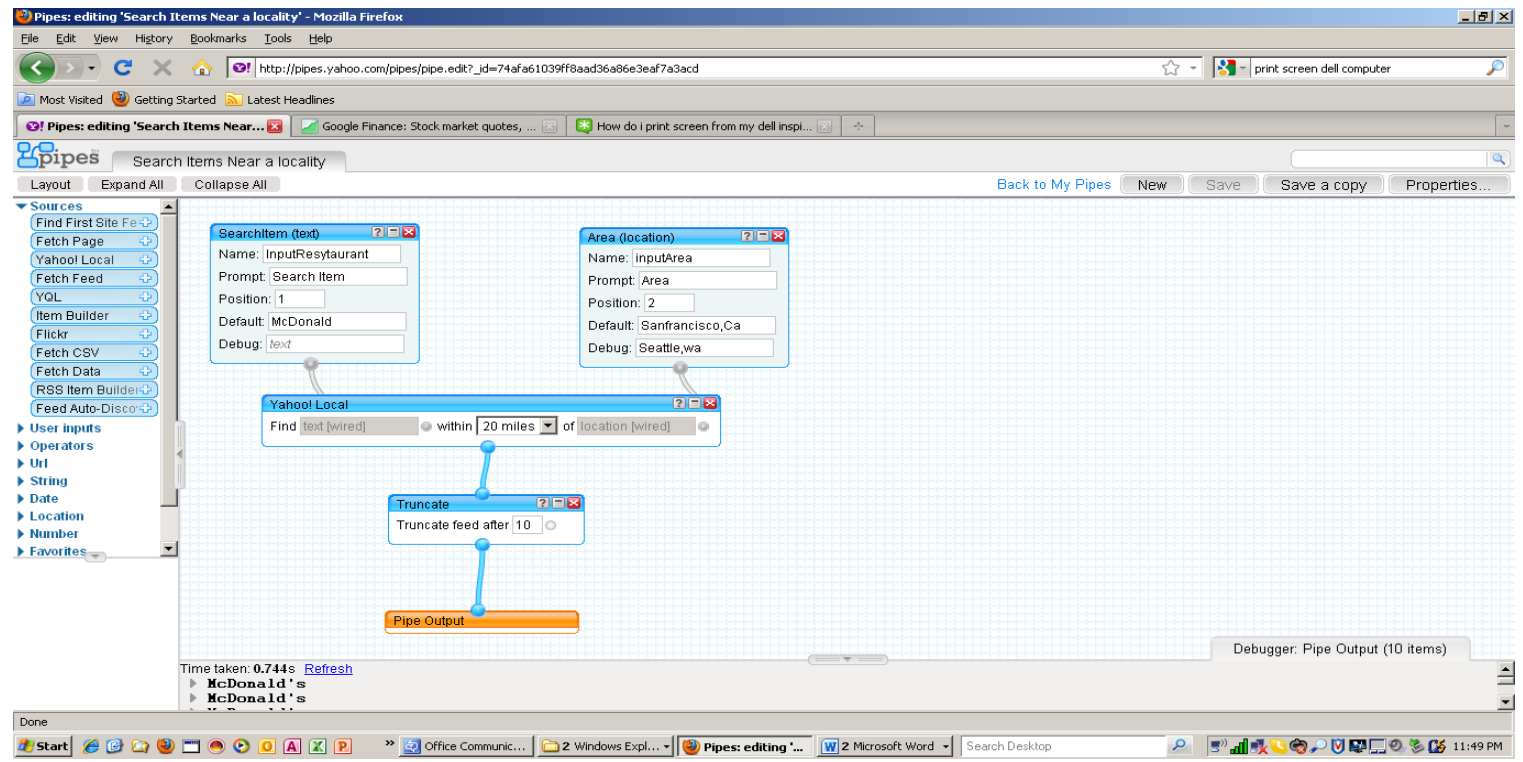

Figure 1: Coding Example -Search Yahoo Local for topics such as "Mcdonald" restaurants in Sanfrancisco Area

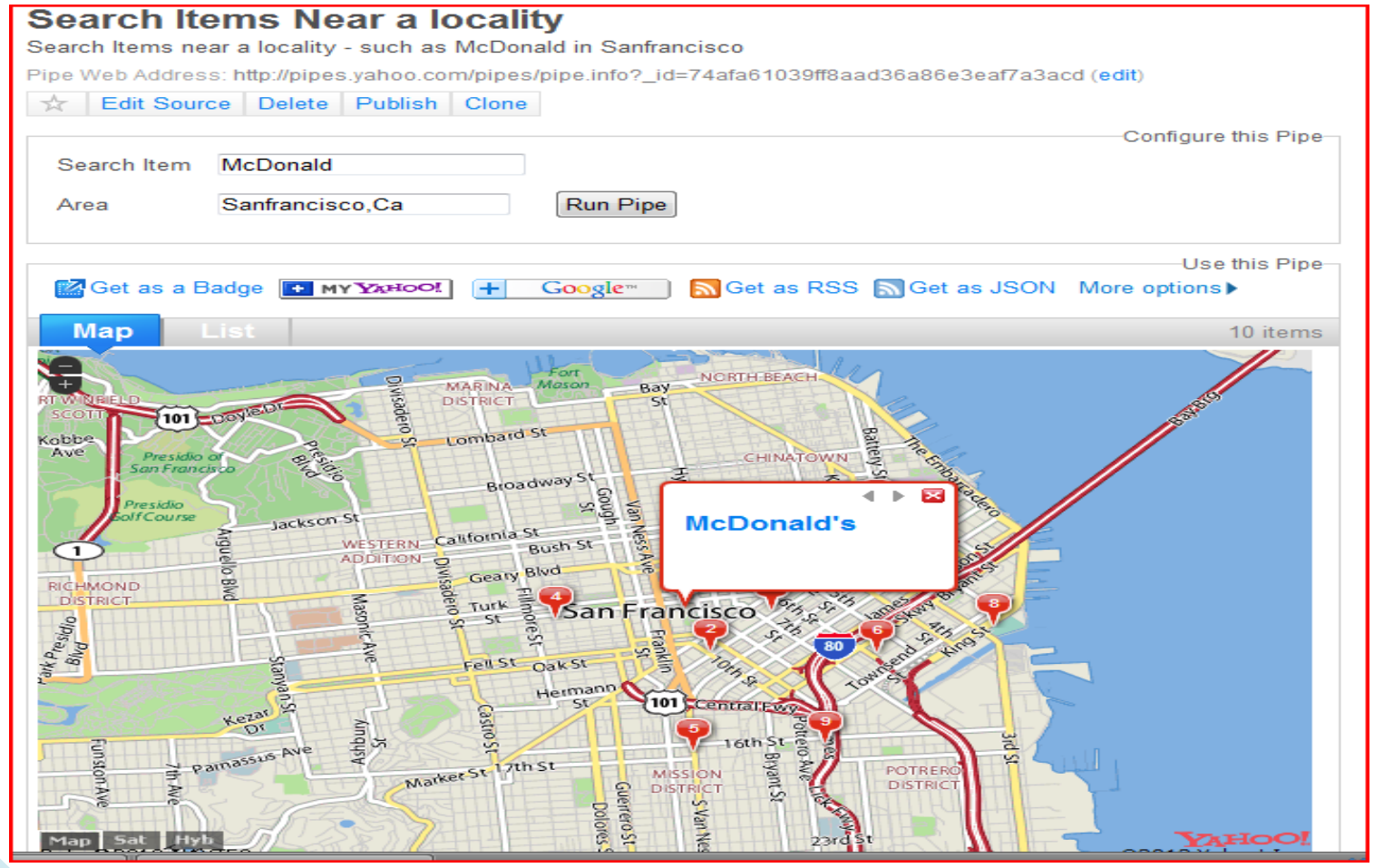

Figure 2: Output of Example 1 


\section{Issues in Information Systems}

Volume 13., Issue No., pp. No., 2012

Example 2: Search images using Flickr (http://tinyurl.com/c3yfg6c )

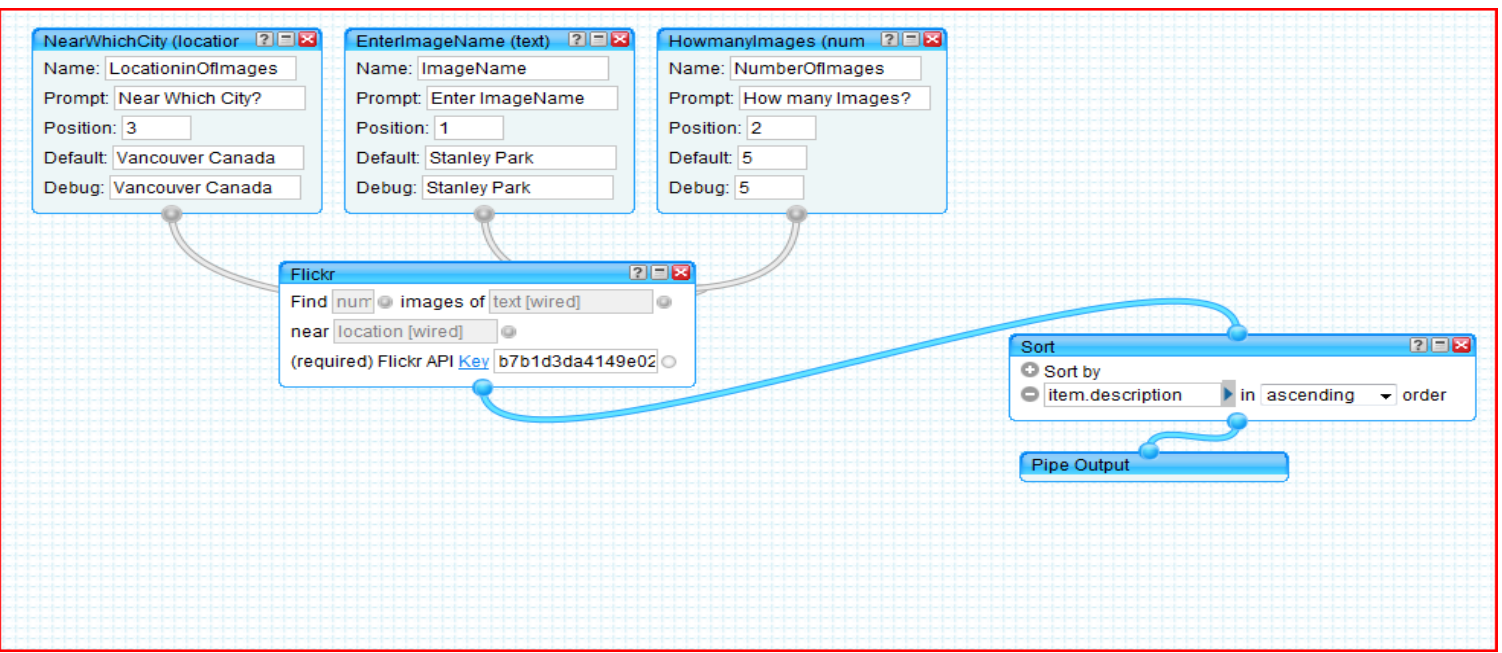

Figure 3: Coding Example -Display Images using Flickr

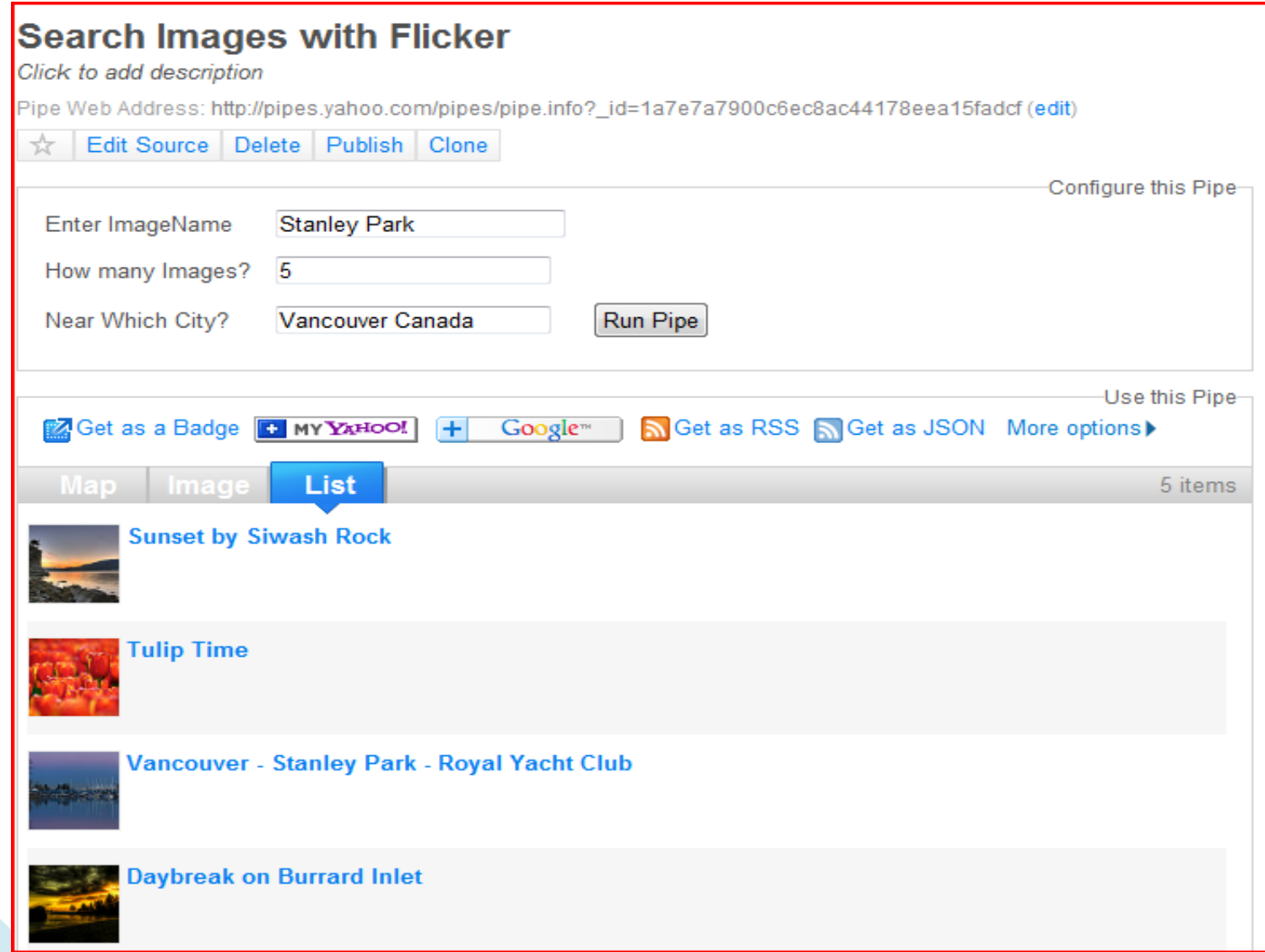

Figure 4: Output of Example 2 


\section{Issues in Information Systems}

Volume 13., Issue No., pp. No., 2012

Example 3: $\underline{\text { Sort and Translate (http://tinyurl.com/bq5337a) }}$

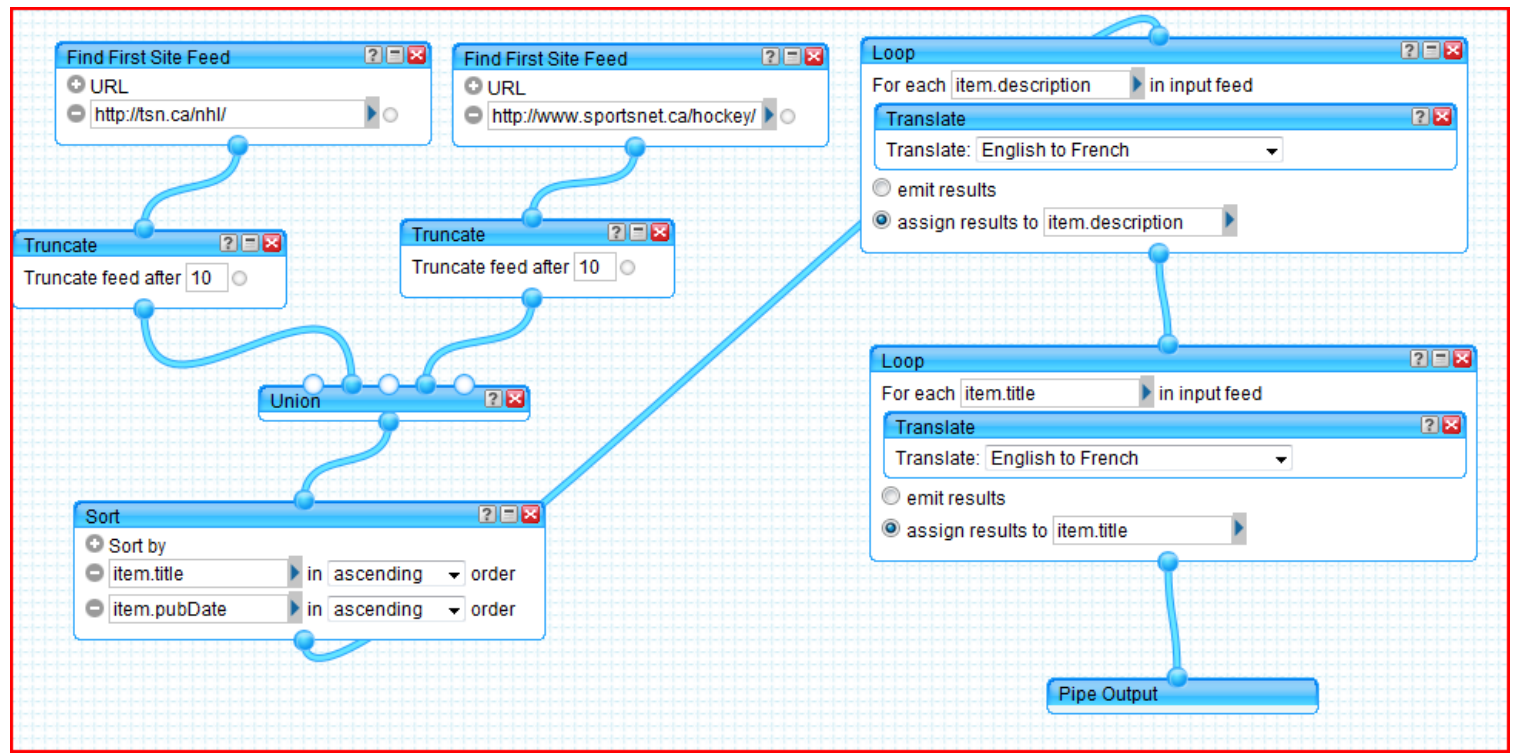

Figure 5: Coding Example-Get news on Hockey and translate to French from English

\section{Sort and Translate}

Click to add description

Pipe Web Address: http://pipes.yahoo.com/pipes/pipe.info?_id=XvWZKBFw3hGmhsztjC6dVQ (edit)

it Edit Source Delete Publish Clone

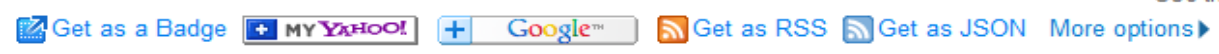

List 20 items

Angelidis marque le premier but de NHL en tant que vestes de battement de foudre Allez à TSN.ca pour des détails. \#TSN

1. $1 y^{v_{2}}$ Évasion de coyotes avec la victoire controversée au-dessus de Sens

1. 1 Daniel Alfreddson a fait onduler un but au loin dans le troisième en raison dune pénalité de gardien de Q 1 but-interférence et des coyotes tenus dessus pour battre les sénateurs.

Les coyotes se tiennent dessus pour la victoire serrée au-dessus des sénateurs Allez à TSN.ca pour des détails. \#TSN

Grabovski arpente des feuilles dans la victoire sauvage au-dessus des insulaires Mikhail Grabovski a eu quatre points et Clarke MacArthur marqué à 2:06 des heures supplémentaires a soulevé Toronto au-dessus des insulaires de New York mardi.

Hodgson marque le gagnant d'échange de tirs comme graisseurs supérieurs de Canucks Allez à TSN.ca pour des détails. \#TSN

Figure 6: Output of Example 3 


\section{Issues in Information Systems}

Volume 13., Issue No., pp. No., 2012

Example 4: $\underline{\text { String Builder Example (http://tinyurl.com/6oqkdzm) }}$

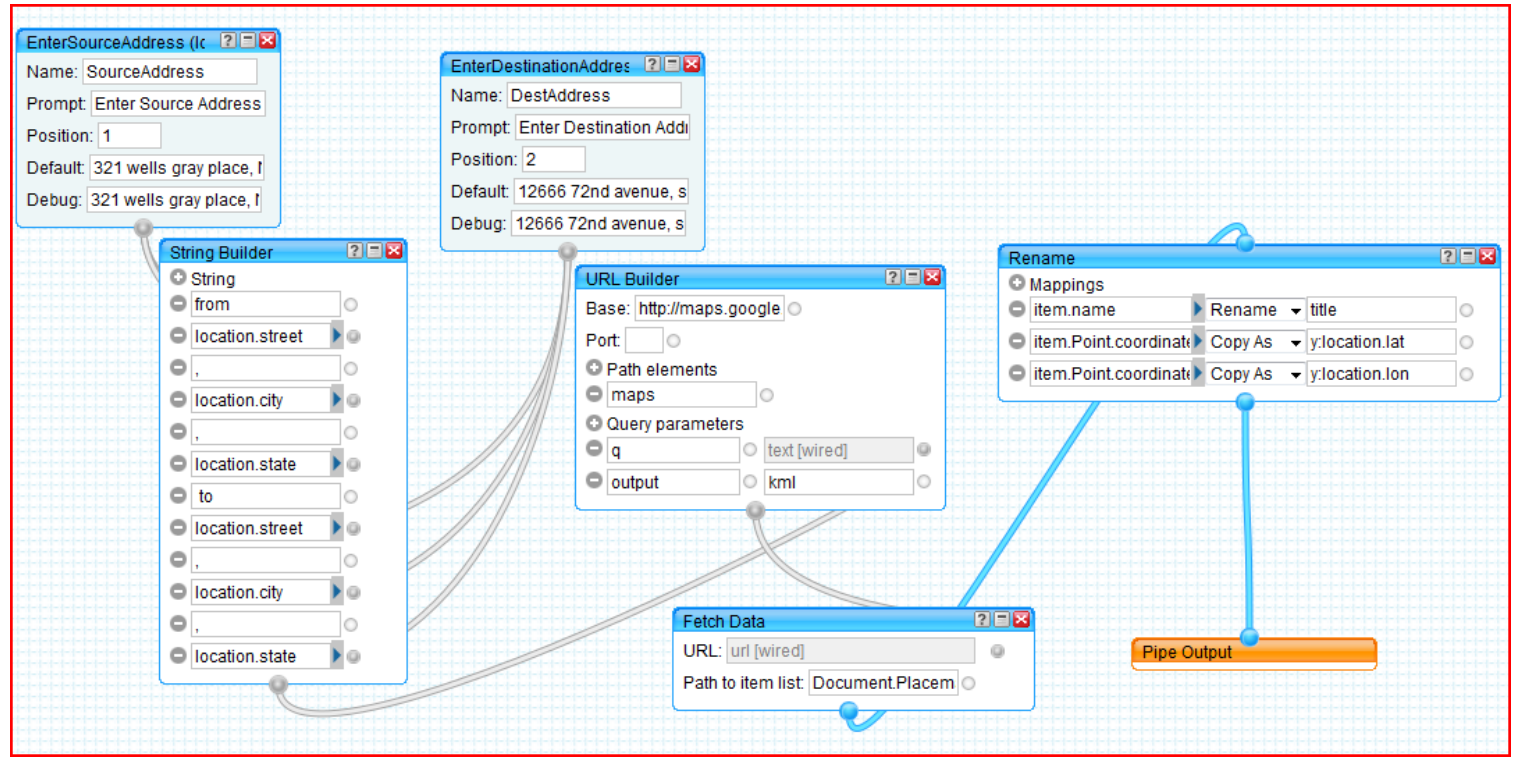

Figure 7: Coding Example-Get driving directions from Google Map

\section{Driving Directions}

This uses Google Maps to calculate distance and travel time between two points

Pipe Web Address: http://pipes.yahoo.com/pipes/pipe.info?_id=602ca3198e5421b1b51d07924c56363d (edit)

th Edit Source Delete Publish Clone

Enter Source Address 321 wells gray place, New

Enter Destination Address Street New Westminster, Run Pipe

Use this Pipe

迶Get as a Badge † MYYaHoO! + Googlem

\begin{tabular}{l|rr} 
Mist & 5 items
\end{tabular}

Head southeast on Wells Gray PI toward 8 Ave

go $75 \mathrm{~m}$

Turn left onto 8 Ave

go $32 \mathrm{~m}$

Turn right onto E Columbia St

go $850 \mathrm{~m}$

Arrive at: E Columbia St, New Westminster, BC, Canada

Route

Distance: $1.0 \mathrm{~km}$ (about 3 mins) Map data @2012 Google

Figure 8: Output of Example 4 